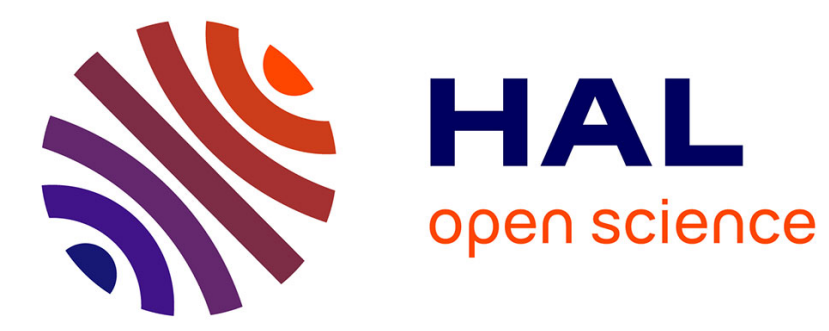

\title{
Migration of nanosized layered double hydroxide platelets from polylactide nanocomposite films
}

Bjørn Schmidt, Vimal Katiyar, David Plackett, Erik Huusfeldt Larsen, Nathalie Gerds, Christian Bender Koch, Jens Højslev Petersen

\section{- To cite this version:}

Bjørn Schmidt, Vimal Katiyar, David Plackett, Erik Huusfeldt Larsen, Nathalie Gerds, et al.. Migration of nanosized layered double hydroxide platelets from polylactide nanocomposite films. Food Additives and Contaminants, 2011, 28 (07), pp.956-966. 10.1080/19440049.2011.572927 . hal-00704679

\section{HAL Id: hal-00704679 \\ https://hal.science/hal-00704679}

Submitted on 6 Jun 2012

HAL is a multi-disciplinary open access archive for the deposit and dissemination of scientific research documents, whether they are published or not. The documents may come from teaching and research institutions in France or abroad, or from public or private research centers.
L'archive ouverte pluridisciplinaire HAL, est destinée au dépôt et à la diffusion de documents scientifiques de niveau recherche, publiés ou non, émanant des établissements d'enseignement et de recherche français ou étrangers, des laboratoires publics ou privés. 


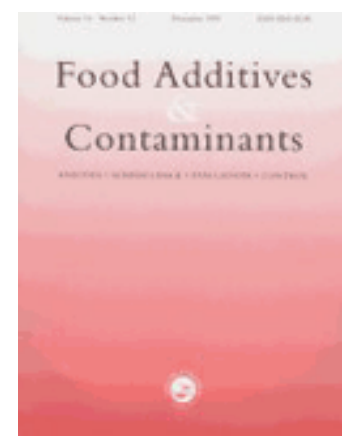

\section{Migration of nanosized layered double hydroxide platelets from polylactide nanocomposite films}

\begin{tabular}{|c|c|}
\hline Journal: & Food Additives and Contaminants \\
\hline Manuscript ID: & TFAC-2010-417.R1 \\
\hline Manuscript Type: & Original Research Paper \\
\hline $\begin{array}{r}\text { Date Submitted by the } \\
\text { Author: }\end{array}$ & 08-Mar-2011 \\
\hline Complete List of Authors: & $\begin{array}{l}\text { Schmidt, Bjørn; Technical University of Denmark, National Food } \\
\text { Institute; University of Copenhagen, Department of Basic Sciences } \\
\text { and Environment } \\
\text { Katiyar, Vimal; Technical University of Denmark, National } \\
\text { Laboratory for Sustainable Energy } \\
\text { Plackett, David; Technical University of Denmark, National } \\
\text { Laboratory for Sustainable Energy } \\
\text { Larsen, Erik; Technical University of Denmark, National Food } \\
\text { Institute } \\
\text { Gerds, Nathalie; University of Copenhagen, Department of Food } \\
\text { Science } \\
\text { Koch, Christian; University of Copenhagen, Department of Basic } \\
\text { Sciences and Environment } \\
\text { Petersen, Jens; Technical University of Denmark, National Food } \\
\text { Institute }\end{array}$ \\
\hline Methods/Techniques: & $\begin{array}{l}\text { ICP/MS, Chromatography - GC, Chromatography, Metals analysis - } \\
\text { ICP/MS }\end{array}$ \\
\hline Additives/Contaminants: & Food contact materials, Food simulants, Migration \\
\hline Food Types: & Meat \\
\hline
\end{tabular}




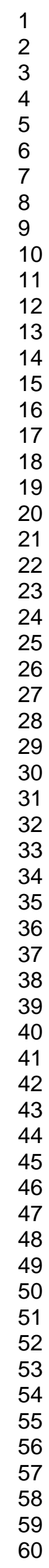

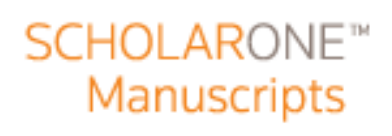

7

25

26

27

29

30

32

33

34

35

36

37

38

40

41

42

44

45

46

47

48

49

51

54

55

57

58

59

60

http://mc.manuscriptcentral.com/tfac Email: fac@tandf.co.uk 


\title{
Migration of nanosized layered double hydroxide platelets from polylactide nanocomposite films
}

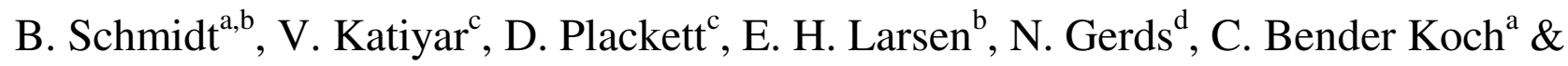 \\ J. H. Petersen ${ }^{\mathrm{b}, 1}$
}

${ }^{a}$ Department of Basic Sciences and Environment, University of Copenhagen, Frederiksberg, Denmark; ${ }^{\mathrm{b}}$ The National Food Institute, Technical University of Denmark, S $\phi b o r g$, Denmark; ${ }^{c}$ Ris $\phi$ National Laboratory for Sustainable Energy, Technical University of Denmark, Roskilde, Denmark; ${ }^{d}$ Department of Food Science, University of Copenhagen, Frederiksberg, Denmark.

\begin{abstract}
Melt-extruded L-polylactide (PLA) nanocomposite films were prepared from commercially available PLA and laurate-modified $\mathrm{Mg}$ - $\mathrm{Al}$ layered double hydroxide $\left(\mathrm{LDH}-\mathrm{C}_{12}\right)$ and three films with different $\mathrm{LDH}-\mathrm{C}_{12}$ loadings. These materials were tested for total migration as well as specific migration of LDH, tin, laurate and low molecular weight PLA oligomers (OLLA). This is the first reported investigation on the migration properties of PLA-LDH nanocomposite films. The tests were carried out as part of an overall assessment of the suitability of such films for use as food contact materials. Total migration was determined according to a European standard method. All three films showed migration of nanosized LDH which was quantified using acid digestion followed by inductively coupled plasma mass spectrometric (ICP-MS) detection of ${ }^{26} \mathrm{Mg}$. Migration of LDH from the films was also confirmed by examining migrates using transmission electron microscopy (TEM) and was attributed indirectly to the significant PLA molecular weight reduction

${ }^{1}$ J. H. Petersen. Email: jhpe @ food.dtu.dk
\end{abstract}


Keywords: migration; nanoparticle; layered double hydroxides; nanocomposite; polylactide; laurate organomodifier

\section{Introduction}

Almost half the global plastic production is currently used in packaging materials and almost half of this amount is used in food packaging (Fomin and Guzeev 2001; Ray and Bousmina 2005). Most of the plastics used in food packaging at present originate from fossil fuels (Lim et al. 2008; Ray and Bousmina 2005; Sorrentino et al. 2007). However, consumer demands call for sustainability and environmental safety and therefore research within green plastics is of great interest (Bordes et al. 2009; Ray and Bousmina 2005; Fomin and Guzeev 2001). Biopolymers derived from renewable resources such as agricultural crops or crop residues meet the demands of sustainability and are environmentally friendly (Garlotta 2001; Ray and Bousmina 2005; Auras et al. 2004; Martin and Averous 2001; Lunt 1998; Sinclair 1996). Unfortunately, in comparison with conventional plastics used in packaging, biopolymers can suffer from reduced thermal stability, poor gas barrier properties, low strength, and low melt viscosity (Fomin and Guzeev 2001; Ray and Bousmina 2005; Sorrentino et al. 2007). These inherent properties can in principle be improved by incorporation of 
engineered or natural nanoparticles (NPs), resulting in biopolymer nanocomposite materials (Bordes et al. 2009; Chang et al. 2003; Ray and Bousmina 2005; Sorrentino et al. 2007; Pluta et al. 2006; Ray et al. 2002; Arora and Padua 2010). Biopolymer nanocomposites have potential as food contact materials (FCM) and can roughly be divided into four categories (Chaudhry et al. 2008): 1) FCM with improved physical properties through incorporation of NPs, 2) active FCM where the incorporated NPs provide antimicrobial activity, 3) intelligent FCM in which the NPs can act as a sensor monitoring the condition of food during transport and storage, and 4) degradable or compostable biopolymer nanocomposites. Research on biopolymer nanocomposites as FCM has mainly focused on categories 1 and 4. In particular, degradable or compostable biopolymers with layered silicate clay minerals as fillers, aiming at enhanced barrier properties, have received attention because of the possibility to prolong the shelf life of foodstuffs packed under modified atmosphere (MAP)(Arora and Padua 2010; Bordes et al. 2009; Ray and Bousmina 2005; Sorrentino et al. 2007). One of the promising biopolymers in this respect is the aliphatic polyester Lpolylactide (PLA). L-lactic acid, typically obtained from starch, is the building block for PLA and a frequently used industrial production route involves conversion to the L-lactide dimer followed by ring-opening polymerization (ROP) in the presence of an organotin catalyst. PLA is considered to be compostable and degrades via initial chain scission of the ester linkages (Garlotta 2001). Reports indicate that PLA can degrade in the environment in a matter of months, whereas conventional plastics such as polystyrene and polyethylene may persist for hundreds of years (Sinclair 1996). In addition to silicate clay minerals as fillers in nanocomposites, layered double hydroxides (LDHs) have attracted interest during the last few years. LDHs are synthesised in the laboratory under controlled conditions, and the presence of trace metals which occur in natural clays can therefore be controlled. Only a limited number of publications exist on the preparation and characterization of PLA-LDH nanocomposites (Chiang and Wub 2008; Chiang and Wu 2010; Chiang et al., 2011; 
Dagnon et al. 2009; Katiyar et al. 2010; Pan et al. 2008; Mahboobeh et al. 2010). In order to ensure compatibility with and good dispersion in bioplastics such as PLA, treatment of LDHs with organomodifiers is generally necessary.

A food safety concern exists when using nanocomposites as food packaging materials because the consumer might be exposed to NPs through their migration into foodstuffs and drinks (Simon et al. 2008). Only a few studies on this issue have yet been published (Schmidt et al. 2009; Avella et al. 2005; Avella et al. 2007) and it is generally concluded that little or no migration of inorganic NPs can be detected from the nanocomposites. This finding is in general agreement, although not directly comparable, with a theoretical assessment of NP migration rates from polymer nanocomposite food packaging materials based on physicochemical considerations (Simon et al. 2008). According to the current EU regulation on food contact materials "substances deliberately engineered to particle size which exhibit functional physical and chemical properties that significantly differ from those at a larger scale" should be risk assessed on a case-by-case basis until more information is available about such new technology (European Commission 2009). The European Food Safety Authority (EFSA) is empowered to make such assessments and to provide an opinion for the European Commission. Until now only titanium nitride (TiN) NPs, intended to be used as an additive in polyethylene terephthalate (PET) bottles, has been allowed in the EU for use in amounts up to $20 \mathrm{mg} \mathrm{kg}^{-1}$ plastic. TiN NPs with a diameter of $20 \mathrm{~nm}$ have been incorporated in PET and tests have shown no sign of migration into food simulants down to the detection limit of five $\mu \mathrm{g} \mathrm{kg}^{-1}$. EFSA opinions are usually based on data from toxicological testing, physical/chemical data and results of migration tests. The evaluation of TiN NPs was based on physical/chemical data and migration tests only and no toxicological data were needed in the evaluation since no NP migrated (EFSA 2008). 
The aim of the study described here was to determine the total and specific migration of all major constituents in the various prepared PLA/laurate-modified Mg-Al layered double hydroxide (PLA$\mathrm{LDH}-\mathrm{C}_{12}$ ) non-commercial nanocomposite films. $\mathrm{LDH}-\mathrm{C}_{12}$ was added with the purpose of reducing gas permeability in order for the films to be used for meat packaging in modified atmospheres. Specific migration tests focused on the detection of $\mathrm{LDH}$, the laurate organomodifier, the organotin catalyst applied and low molecular weight PLA oligomers (OLLA). In parallel with these studies, chemical and physical characterization of melt-extruded PLA- LDH-C ${ }_{12}$ films, including thermal stability and barrier properties, has been undertaken and is the subject of another publication (Katiyar et al. 2011).

\section{Materials and methods}

Synthesis of $\mathrm{LDH}-\mathrm{C}_{12}$

LDH-C $\mathrm{C}_{12}$ was synthesized using a reconstruction method for the intercalation of laurate anions. $\mathrm{LDH}-\mathrm{CO}_{3}, \mathrm{Al}\left(\mathrm{NO}_{3}\right)_{3} \cdot 9 \mathrm{H}_{2} \mathrm{O}, \quad \mathrm{Mg}\left(\mathrm{NO}_{3}\right)_{2} \cdot 6 \mathrm{H}_{2} \mathrm{O}, \mathrm{Na}_{2} \mathrm{CO}_{3}, \mathrm{NaNO}_{3}$ (Merck KGaA, Darmstadt, Germany) and $\mathrm{NaOH}$ (Mallinckrodt Baker B.V., Deventer, Netherlands) were used for the synthesis of the $\mathrm{LDH}-\mathrm{CO}_{3}$. Ethanol (96\%, Kemertyl A/S, Køge, Denmark) and Decanoic acid (lauric acid) (Sigma-Aldrich Chemie GmbH, Munich, Germany) were used for the modification of the synthesised LDH.

The precursor $\mathrm{LDH}-\mathrm{CO}_{3}$ was prepared by a constant $\mathrm{pH}$-stat co-precipitation method similar to Miyata (1975). 1.5 Liter of a $1 \mathrm{~mol} \mathrm{Al}\left(\mathrm{NO}_{3}\right)_{3} \cdot 9 \mathrm{H}_{2} \mathrm{O}$ solution was slowly transferred to a $15 \mathrm{Liter}$ bucket containing 5 Liter of 3 mole $\left.\mathrm{Mg}\left(\mathrm{NO}_{3}\right)_{2} \cdot 6 \mathrm{H}_{2} \mathrm{O}\right)$ solution over a period of $8 \mathrm{~h}$. The $\mathrm{pH}$ of the reaction mixture was adjusted to 9 by addition of $2 \mathrm{M} \mathrm{NaOH}$ and $0.2 \mathrm{M} \mathrm{Na}_{2} \mathrm{CO}_{3}$ solution. The synthesis was carried out at room temperature and the suspension was constantly stirred during 


\section{Processing of PLA and PLA-LDH-lauric acid nanocomposite films (PLA-LDH-C 12 )}

PLA-film and PLA-LDH-C ${ }_{12}$ nanocomposite films were processed using PLA (Grade 2003D) from NatureWorks ${ }^{\circledR}$ LLC (Minnetonka, MN, USA) which was dried at $100^{\circ} \mathrm{C}$ for four hours prior to processing into films. Neat PLA or PLA with LDH-C 12 was compounded into pellets using a twinscrew co-rotating extruder (Jiangyu Xinhua Plastics Machinery Co. Ltd., Wuxi, Shanghai, China) with an attached three-hole strand die (three mm), cooling bath and pelletizer. $\mathrm{LDH}-\mathrm{C}_{12}$ was introduced into PLA either by direct compounding with PLA or by addition of $10 \%$ previously prepared PLA-50\% LDH-C ${ }_{12}$ masterbatch. In short, the masterbatch was prepared by an in situ intercalative ROP method in which an LDH-C $\mathrm{C}_{12}$ and L-lactide mixture (1:1 weight ratio) was first prepared using dichloromethane as solvent. The dried mixture was then polymerized in the presence of tin(II) 2-ethyl hexanoate as catalyst ( 95\%, Sigma Aldrich, Brøndby, Denmark), yielding the aforementioned PLA-LDH-C 12 masterbatch with 5\% nanofiller loading. Neat PLA pellets were processed under the same conditions so the reference pellets would have the same thermal history as the nanocomposite pellets. Dry PLA and PLA-LDH-C ${ }_{12}$ pellets were then converted into films 
using a single screw extruder (Labotech Engineering Company Ltd., Bangkok, Thailand). A detailed description of the film processing can be found elsewhere (Katiyar et al. 2010). Nomenclature and a description of the materials are presented in Table 1.

\section{Migration studies \\ Migration test procedure \\ The migration test procedure used 95\% ethanol (HPLC grade $\geq 99.9 \%$, Merck, Darmstadt, Germany) and 5\% water (glass-distilled) as a simulant substituting fatty foods in accordance with European Union legislation (Comité Europeén de Normalisation (CEN) 2002; Comité Europeén de Normalisation (CEN) 2004; European Commission 2002). One $\mathrm{dm}^{2}$ from each type of PLA and PLA-LDH-C $\mathrm{C}_{12}$ film was fully immersed into $100 \mathrm{ml}$ of simulant and both sides were exposed at $40^{\circ} \mathrm{C}$ for 10 days. Simulant blanks, simulant spiked with $\mathrm{LDH}-\mathrm{C}_{12}$ and simulant spiked with lauric acid ( $\geq 99 \%$ for synthesis, Merck, Hohenbrunn, Germany) were included. All migrates were analysed in triplicate except for the blank, which was analysed in duplicate. Three series of tests were performed for the purpose of determining total migration and specific migration of LDH, tin, laurate and low molecular weight PLA oligomers (OLLA).}

\section{Analysis of total migration}

Total migration from the nanocomposites (mass of migrant per $\mathrm{dm}^{2}$ ) was determined gravimetrically using a modification of the laboratory-accredited CEN-procedure in which the film samples were removed after exposure and the simulant evaporated to dryness (Comité Europeén de Normalisation (CEN) 2002). The rather volatile laurate constitutes in some samples a significant part of the total migration and was to some extent lost during the prescribed repeated heating, drying, and weighing cycle prescribed by the migration test method. This was investigated by 


\section{Analysis of specific migration of laurate}

From each $100 \mathrm{ml}$ food simulant migrate, $20 \mathrm{ml}$ was removed for laurate analysis. Migrates were evaporated almost to dryness and the residue was then resuspended in refluxing cyclohexane. An internal standard (heptadecanoic acid, $>99 \%$, Fluka, Steinheim, Germany) was added, followed by $10 \mathrm{ml} \mathrm{KOH} \mathrm{(11} \mathrm{mg} \mathrm{ml}{ }^{-1}$, Pro Analysis, Merck KGaA, Darmstadt, Germany) and then five ml boron-trifluoride-methanol complex (150 $\mathrm{mg} \mathrm{BF}_{3} \mathrm{ml}^{-1}$, Merck, Hohenbrunn, Germany). Finally, 15$20 \mathrm{ml}$ deionised water saturated with $\mathrm{Na}_{2} \mathrm{SO}_{4}$ was added to give a two-phase system. The upper organic phase contained lauric acid methyl esters, which were quantified using gas chromatography (GC) with flame ionization detection (FID). The GC was an Agilent 6890A (Agilent Technologies, Santa Clara, CA, USA). Raw data were collected using Agilent Chemstation Software (ver. A1002). The GC column was a non-polar Agilent J\&W DB1 (30 m, i.d. $0.25 \mathrm{~mm}$, film thickness 0.25 $\mu \mathrm{m}$ ) kept at $80^{\circ} \mathrm{C}$ for one minute, ramping with $15^{\circ} \mathrm{C} \min ^{-1}$ to $300^{\circ} \mathrm{C}$, which was maintained for five minutes. The carrier gas was helium (column flow about $40 \mathrm{~cm} \mathrm{sec}^{-1}$ ). A one $\mu 1$ split injection at $250^{\circ} \mathrm{C}$ was used in the analyses (split 1:100). Lauric acid standards were included in the derivatisation process in a range of concentrations corresponding to a migration of laurate from 0 $\mathrm{mg} \mathrm{dm} \mathrm{m}^{-2}$ to $10.6 \mathrm{mg} \mathrm{dm}^{-2}$. The linearity of the laurate standard curve was reflected by a correlation coefficient $\left(\mathrm{R}^{2}\right)$ exceeding 0.996 and the limit of detection was $0.2 \mathrm{mg} \mathrm{dm}{ }^{-2}$. 
Analysis of the specific migration of $\mathrm{LDH}$ and tin

From each of the $100 \mathrm{ml}$ food simulant migrates the remaining $80 \mathrm{ml}$ served as samples for analysis of migrated LDH- $\mathrm{C}_{12}$ and tin. The samples were reduced to $20 \mathrm{ml}$ by evaporation, from which 12 $\mathrm{ml}$ was transferred to Teflon inserts for further acid digestion following method 3052 of the US Environmental Protection Agency (USEPA) (United States Environmental Protection Agency 1996). These aliquots were then evaporated almost to dryness in a heated water bath and the following were added to all inserts in the order mentioned: two $\mathrm{ml}_{2} \mathrm{O}_{2}$ (Suprapur $30 \%$, Merck, Darmstadt, Germany), nine ml $\mathrm{HNO}_{3}$ (PlasmaPURE 67-69\%, SCP Science, Champlain, NY, USA), two ml HCl (PlasmaPURE 34-37\%, SCP Science, Champlain, NY, USA) and three ml HF (Suprapur 40\%, Merck, Darmstadt, Germany). In the next step, the Teflon inserts were enclosed in steel bombs and placed in an oven at $180^{\circ} \mathrm{C}$ for six hours and the contents transferred quantitatively to $50 \mathrm{ml}$ conical polypropylene tubes (Sarstedt AG \& Co. Nümbrecht, Germany) containing $20 \mathrm{ml}$ of $6 \%$ boric acid (Puratronic 99.9995\% from Alfa Aesar GmbH \& Co KG, Karlsruhe, Germany). Milli-Q water was added to a final volume of $45 \mathrm{ml}$. The acid-digested samples were analysed for tin and magnesium $(\mathrm{Mg})$ in two different sequences by inductively coupled plasma mass spectrometry (ICP-MS, Agilent 7500ce system, Agilent Technologies, Santa Clara, CA, USA) equipped with a cooled Scott-type spray chamber and an Agilent micro flow nebulizer (model no. G3139A-100). The ICP-MS was run in spectrum analysis acquisition mode with an uptake flow rate of $0.33 \mathrm{ml} \mathrm{min}{ }^{-1}$ and the RF power set to $1550 \mathrm{~W}$. Raw data were collected on Agilent Chemstation Software (version B.03.05).

The LDH analyses were conducted by measuring the isotope ${ }^{26} \mathrm{Mg}$ with ${ }^{103} \mathrm{Rh}$ (rhodium standard for ICP-MS, PlasmaCAL, SCP Science) as an internal standard. Non-cell mode was applied with an integration time per mass set to $0.3 \mathrm{~s}$ with three repetitions. The acid-digested samples were diluted before analysis by adding one $\mathrm{ml}$ acid-digested sample to $25.1 \mathrm{ml}$ of $2 \% \mathrm{HNO}_{3}$ containing $10 \mu \mathrm{g} \mathrm{Rh}$ 


\section{Analysis of specific migration of low molecular weight PLA oligomers}

In order to qualitatively determine the specific OLLA migration, each $100 \mathrm{ml}$ portion of food simulant was evaporated to dryness under reduced pressure at room temperature. An OLLA residue was visible in the case of the neat PLA sample (PLA-PF) and particulate matter was also visible in the residues after evaporation in the PLA-LDH-C 12 film samples (PLA-PF1, PLA-PF2 and PLAPF3). The residues were redissolved in two $\mathrm{ml} \mathrm{CHCl}_{3}(>99.8 \%$, Sigma Aldrich, Brøndby, Denmark). In order to avoid gel permeation chromatography (GPC) column contamination or clogging by large particles, the redissolved migrates were filtered through a $0.20 \mu \mathrm{m}$ Whatman ${ }^{\circledR}$ filter before analysis. $100 \mu \mathrm{l}$ of each sample was injected into the GPC system (model LC-10AD, 
Shimadzu Europa GmbH, Duisburg, Germany) equipped with a refractive index detector (Model 200, Viscotek Corporation, Houston, TX, USA) and with 5 $\mu$ Mixed-C and a $5 \mu$ Mixed-D PLgel columns (300 mm, i.d. 7.5 mm, Polymer laboratories Ltd (through Scantec Lab AB, Sävedalen, Sweden) in series, with tetrahydrofuran (THF) (HPLC grade, Sigma Aldrich, Brøndby, Denmark)

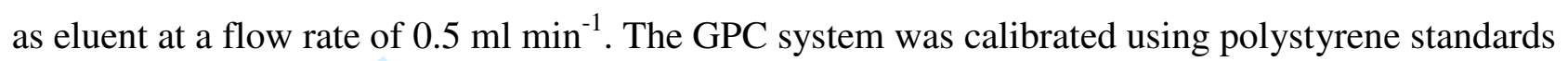
dissolved in THF in a range between $1.2 \mathrm{kDa}$ and $680 \mathrm{kDa}$. PLA molecular weights (MW) and a relative concentration factor $(\mathrm{CF})$ for OLLA in migrant samples were calculated. PLA molecular weights were expressed in terms of number average molecular weights $\left(M_{n}\right)$.

\section{Film characterization before and after migration study}

Neat PLA and PLA-LDH-C 12 nanocomposite films were characterized with respect to numberaverage molecular weight $\left(\mathrm{M}_{\mathrm{n}}\right)$, weight-average molecular weight $\left(\mathrm{M}_{\mathrm{w}}\right)$, and polydispersity index $\left(\mathrm{PDI}=\mathrm{M}_{\mathrm{w}} / \mathrm{M}_{\mathrm{n}}\right.$ ) before and after exposure to the food simulant using the GPC system described above. The procedure used for the molecular weight analysis of these films was similar to that for OLLA. In order to avoid LDH or larger particles plugging the GPC column, the PLA-LDH-C 12 nanocomposite solutions in chloroform were kept for 24 hours at room temperature for particles to settle and the supernatant was filtered through a $0.45 \mu \mathrm{m}$ Whatman ${ }^{\circledR}$ filter.

\section{Electron microscopy}

Scanning electron micrographs (SEM) on $\mathrm{LDH}-\mathrm{C}_{12}$ powder samples were obtained using a FEI Quanta 200F field emission gun microscope (FEI Company, Hillsboro, OR, USA) operated at an accelerating voltage of $5 \mathrm{kV}$. The powder samples were placed on carbon tape and coated with a 20 nm thick layer of carbon using a vacuum sputtering technique. 


\section{Results and discussion}

\section{Migration studies}

\section{Total migration}

The results obtained for total migration measurements are reported in Table 4. It is apparent that LDH- $\mathrm{C}_{12}$ loading may influence total migration since the lowest total migration is found for the neat PLA film (PLA-PF) and total migration values increase with increasing LDH-C 12 loading (PLA-PF1 (1.8\%), PLA-PF3 (1.8\%) and PLA-PF2 (5.5\%)). The migration limit for overall migration is $10 \mathrm{mg} \mathrm{dm}^{-2}$ and only the migration from PLA-PF2 is higher, at about $32 \mathrm{mg} \mathrm{dm}^{-2}$. However, the films produced in this project are intended for the packaging of fresh meat in which case a reduction factor of four should be applied to the migration test result with a fatty food simulant before comparing with the legislative limit (European Commission 2010). The corrected result for PLA-PF2 was therefore $8 \mathrm{mg} \mathrm{dm}^{-2}$, which is well below the total migration limit. The recovered content of $\mathrm{LDH}-\mathrm{C}_{12}$ in spiked simulants was $5.2 \mathrm{mg}$ and, compared to the $5.0 \mathrm{mg}$ of $\mathrm{LDH}-\mathrm{C}_{12}$ originally spiked to the simulant corresponds to a recovery of $104 \%$ which supports the accuracy of the total migration study. 


\section{Specific migration of tin}

Tin migration was only detected in the case of the PLA-PF2 and PLA-PF3 nanocomposite films

(Table 4). This was expected since these two films are the ones prepared from the PLA-50\% LDH$\mathrm{C}_{12}$ masterbatch, which was made by in situ intercalative ROP using tin (II) 2-ethyl hexanoate catalyst. The tin (II) 2-ethyl hexanoate catalyst is not on the EU positive list, but is accepted by the US Food and Drug Administration for use only as a catalyst for polyurethane resins and in epoxy coatings (US Food and Drug Administration 2010). Although, it is not required that catalysts used for FCM are on the EU positive list, a limit for the sum of more toxic organotin substances (typically used as PVC-stabilisers) of $6 \mu \mathrm{g}$ tin $\mathrm{kg}^{-1}$ food or $1 \mu \mathrm{g}$ tin $\mathrm{dm}^{-2}$ exists (European Commission 2002). Both PLA-PF2 and PLA-PF3 show migration of tin at about this level.

\section{Specific migration of $\mathrm{LDH}$}

LDH-C ${ }_{12}$ content recovered in the spiked simulant was $4.0 \mathrm{mg}$ (Table 4), which corresponds to a recovery of $80 \%$ as $5.0 \mathrm{mg}$ was originally spiked to the food simulant. The stoichiometry between LDH and laurate was not known, and this is why it was chosen to express the migration of LDH from the films as $\mathrm{LDH}-\mathrm{C}_{12}$. However, this will overestimate the amount of LDH NPs migrating since we relate $\mathrm{Mg}$ measured by the ICP-MS to the weighed mass of $\mathrm{LDH}-\mathrm{C}_{12}$ and because LDH$\mathrm{C}_{12}$ is not completely free of water. The highest value of LDH-C $\mathrm{C}_{12}$ migration was detected in the sample with the highest clay loading (PLA-PF2). Migration from the two other nanocomposite films were in the same order of magnitude due to their similar $\mathrm{LDH}-\mathrm{C}_{12}$ loading. The decrease in PLA molecular weight during the migration study can perhaps explain LDH- $\mathrm{C}_{12}$ migration from the films. A higher rate of platelet migration could reflect a general increase in diffusivity that might be expected in a polymer matrix with lower molecular weight and hence higher free volume. However, 


\section{Specific migration of laurate}

The results of the specific migration measurements can be found in Table 4. An interesting finding in the spike experiments was the very low amount of free laurate released from $\mathrm{LDH}-\mathrm{C}_{12}$ into the simulant compared to the release from the nanocomposite films. This was most likely because laurate anions are strongly bound by ionic forces within the LDH platelet galleries. However, migration of laurate was observed and quantified in the case of PLA-LDH-C 12 nanocomposite films, indicating that lauric acid was either liberated from LDH during processing of the PLA films or during the migration study. Notably, there was no significant difference between specific laurate migration from films PF-1 and PF-3 produced by different compounding methods but with similar LDH-C $_{12}$ loadings.

In an earlier study, significant migration of the organomodifier from exfoliated Cloisite ${ }^{\circledR} 30 \mathrm{~B}$ was seen in tests of PLA films containing this organomodified montmorillionite clay. Attention should therefore be given to organomodifier migration and potential food safety issues (Sharma et al. 2010) as well as to the NPs (Scientific Committee on Emerging and Newly Identified Health Risks (SCENIHR) 2006). Arguably, greater migration of an organomodifier might be expected in cases where a higher extent of clay exfoliation has been achieved. In the case of laurate migration studied here, there should be no toxicity concerns given the low levels of migration detected. It should, however, be mentioned that lauric acid had a noticeably unpleasant smell when heated. A phenomenon, which was observed during the repeated heating, drying, and weighing cycles of the migrates as well as during the extruding process. This would be of concern in the context of food packaging since the EU framework directive (European Commission 2004) prescribes that FCM 
should not transfer their constituents to food in quantities which could bring about a deterioration in the organoleptic characteristics of the food.

\section{Characterization of films before and after migration studies}

Figure 1 shows the gel permeation chromatograms and Table 2 summarizes the molecular weights and molecular weight distributions of the processed films before and after exposure to food simulant. Clearly, PLA molecular weights decreased during migration testing in all films. The decrease in $M_{n}$ of PLA-PF was $\sim 24 \%$ but was in the range $36-38 \%$ for samples PLA-PF1, PLA PF2 and PLA-PF3 A greater decrease in polymer molecular weight attributed to hydrolysis in PLALDH films may be associated with a catalytic effect introduced by the presence of nano-dispersed LDH platelets with many available hydroxyl groups and metal sites on the platelet surfaces. As noted by Zhang et al. (1997), encapsulated metal salts, including hydroxides, can have a significant influence on water uptake and degradation in poly(D,L-lactide-co-glycolide) and reasons such as: 1$)$ changes in film porosity, 2) osmotic forces, 3) neutralization of protons released during hydrolysis of ester linkages, and 4) chemical interactions between ions and functional groups on the polymer, were suggested. In this work, the interaction between PLA and the inorganic additive (i.e., LDH) is likely enhanced by its dispersion in nano-form. The PDI of the PLA films increased during the migration test period along with decreasing $M_{n}$ regardless of the film type, which could be explained by the formation of low molecular weight PLA oligomers (OLLA). It is feasible that OLLAs could migrate from PLA films into the food simulant during migration testing and this was therefore investigated.

\section{Specific Migration of OLLA}


The GPC chromatograms of the migrate solutions are shown in Figure 2 and the $\mathrm{M}_{\mathrm{n}}$ values corresponding to peaks for OLLAs in each sample are presented in Table 3. Three resolved GPC peaks (peaks 1-3) were identified in these samples, suggesting a wide range of OLLA chains migrating into the food simulant. The longer OLLA chains ( $\mathrm{Mn} \geq 3000 \mathrm{Da}$ ) corresponds to peak 1 in Figure 2 and peaks 2 and 3 represent lower molecular weight OLLA. The presence of OLLA in migrates from all film samples were further examined using ${ }^{1} \mathrm{H}-\mathrm{NMR}$ analysis and the presence of OLLA was confirmed (data not shown).

In order to provide an estimate for the increase in OLLA migrating from the PLA nanocomposite films compared to the neat PLA film the areas under the three GPC peaks (Figure 3) were integrated and compared. A relative OLLA concentration factor (CF) was calculated by taking the sum of all three peak areas for each sample and relating the sum to the same value in the GPC output from neat PLA (PLA-PF). The relative values can be found in Table 3. It is observed that the $\mathrm{CF}$ is higher at the higher $\mathrm{LDH}-\mathrm{C}_{12}$ loading (PLA-PF2) which may indicate a relationship between LDH-C ${ }_{12}$ loading and migrating OLLA. However, interestingly, the OLLA CF is lower in the case of PLA-LDH-C ${ }_{12}$ film based on the masterbatch (PLA-PF3) compared to the other $1.8 \% \mathrm{w} / \mathrm{w}$ LDH$\mathrm{C}_{12}$ loaded film (PLA-PF1). LDH surface modification by growing PLA chains during masterbatch synthesis and reduced interaction between PLA chains and LDH surface hydroxyl groups as a result, may provide a possible explanation.

\section{Imaging of LDH by SEM}

The microstructure of the $\mathrm{LDH}-\mathrm{C}_{12}$ powder sample show aggregates (diam. $\sim 1 \mu \mathrm{m}$ ) of sheet planar single particles with sand-rose morphology and a diameter particle size $\sim 200 \mathrm{~nm}$ and thickness of $<$ $20 \mathrm{~nm}$ 


\section{Imaging of migrates by TEM}

In the migrate from the PLA-PF sample a residue which may be OLLA was observed (Figure 3b). TEM photomicrographs of migrate samples from PLA-PF1, PLA-PF2 and PLA-PF3 films (Figures $3 \mathrm{c}-\mathrm{f}$ ) show particles that are consistent with the appearance of LDH platelets. EDAX data obtained when focusing on these particles indicated the presence of $\mathrm{Mg}$ and $\mathrm{Al}$, which is chemical evidence supporting this identification of the particles seen in Figures $3 \mathrm{~b}$-e. In the case of the nanocomposite films, the size of the LDH platelets as measured by image analysis was less than $50 \mathrm{~nm}$, which compares with a platelet size from $50 \mathrm{~nm}$ to $200 \mathrm{~nm}$ when $\mathrm{LDH}-\mathrm{C}_{12}$ was examined using TEM after synthesis (Katiyar et al. 2010). This finding may arise due to mechanical separation of the LDH platelets during the melt processing steps. Smaller nanoplatelets will be more likely to diffuse from the PLA film to the food simulant. The finding that $50 \mathrm{~nm}$ NPs migrate in this case is not consistent with the theoretical physicochemical point of view expressed by Simon et al (Simon et al. 2008) who calculated the migratability of $5 \mathrm{~nm}$ particles in plastics with high diffusivity such as lowdensity polyethylene. These authors concluded that any significant migration, even after a long time in contact with foodstuffs, could be expected solely in the case of very small NPs with a radius in the order of $1 \mathrm{~nm}$. However, they also indicate that although their migration test results conform with theory, more testing on other types of materials would be needed to build a broader picture and to confirm the predicted migration patterns for other nanocomposites. Consequently, it is perhaps not surprising that there would be differences in the size of any migrating NPs as a function of NP type and polymer matrix chemistry. Interestingly, we can also observe LDH platelets mixed with OLLA chains in the migrate from PLA-PF3 (Figures 3d and 3e). The possibility that PLA grafted on to LDH surfaces during masterbatch synthesis also participates in migration cannot be discounted (Katiyar et al. 2010). 


\section{Conclusions}

Total migration and specific migration of $\mathrm{LDH}$, tin and laurate from extruded PLA-LDH-C 12 nanocomposite films was analysed. Total migration, as well as specific migration of LDH and laurate, was higher at higher $\mathrm{LDH}-\mathrm{C}_{12}$ loading in the films. Hydrolysis of PLA during migration testing and a consequent reduction in molecular weight may provide the explanation for these findings. Specific migration of tin was quantified and qualitative evidence for OLLA migration was also found. In addition to release of laurate during the migration tests, it is possible that release of laurate from the organomodified LDH may have occurred during melt processing of PLA and LDH$\mathrm{C}_{12}$ which would be another contributing factor. For the first time specific migration of LDH nanoplatelets from nanocomposite films was visualised and the nanoplatelet dimensions confirmed by TEM. This visualisation in combination with elemental analysis by EDAX complemented the quantitative determination by ICP-MS. The use of TEM to examine migrate residues also provided evidence which was consistent with the presence of migrating PLA oligomers.

This paper has focused on examining the migration of particular organomodified LDH NPs from melt-processed PLA films and has demonstrated how standard migration procedures in combination with advanced characterization methods have advanced our knowledge in this particular field. In addition to the findings from this study, there are still other factors to consider before such materials could be considered suitable for food packaging, such as the effect of LDH organomodifiers on organoleptic properties of packaged food, including possible consequences for film use, and which sort of food packaging might be appropriate given the migration properties of any particular PLALDH nanocomposite type.

\section{Acknowledgements}


The authors would like to express their thanks to The Danish Strategic Research Council for supporting the NanoPack (Biopolymer Nanocomposite Films for use in Food Packaging Applications) project (File .no. 2106-06-0061).

\section{Reference List}

Arora, A and Padua, GW. 2010. Review: Nanocomposites in food packaging. J Food Sci. 75:R43R49.

Auras, R, Harte, B, Selke, S. 2004. An overview of polylactides as packaging materials. Macromol Biosci. 4:835-864.

Avella, M, Bruno, G, Errico, ME, Gentile, G, Piciocchi, N, Sorrentino, A, Volpe, MG. 2007. Innovative packaging for minimally processed fruits. Packag Technol Sci. 20:325-335.

Avella, M, De Vlieger, JJ, Errico, ME, Fischer, S, Vacca, P, Volpe, MG. 2005. Biodegradable starch/clay nanocomposite films for food packaging applications. Food Chem. 93:467-474.

Bordes, P, Pollet, E, Averous, L. 2009. Nano-biocomposites: Biodegradable polyester/nanoclay systems. Prog Polym Sci. 34:125-155.

Chang, JH, An, YU, Sur, GS. 2003. Poly(lactic acid) nanocomposites with various organoclays. I. Thermomechanical properties, morphology, and gas permeability. J Polym Sci B Polym Phys. 41:94-103. 
Chaudhry, Q, Scotter, M, Blackburn, J, Ross, B, Boxall, A, Castle, L, Aitken, R, Watkins, R. 2008. Applications and implications of nanotechnologies for the food sector. Food Addit Contam. 25:241-258.

Chiang, MF and Wu, TM. 2010. Synthesis and characterization of biodegradable poly(Llactide)/layered double hydroxide nanocomposites. Compos Sci Technol. 70:110-115

Chiang, MF and Wub, TM. 2008. Thermal degradation of novel exfoliated PLLA/LDH nanocomposites. Adv Mat Res, Pts 1 and 2. 47-50:415-418.

Chiang, MF, Chu MZ, Wu, TM. 2011. Effect of layered double hydroxides on the thermal degradation behavior of biodegradable poly(L-lactide) nanocomposites. Polym Degr Stab. 96:60-66.

Comité Europeén de Normalisation (CEN).2002. EN 1186: Materials and articles in contact with foodstuffs - plastics. Part 1: Guide to the of conditions and test methods for overall migration. Part 14: Test method for substitute test for overall migration into isooctane and 95\% aqueous ethanol. Brussels:CEN.

Comité Europeén de Normalisation (CEN). 2004. EN 13130-1: Materials and articles in contact with foodstuffs - Plastic substances subject to limitation - Part 1: Guide to test methods for the specific migration of substances from plastics to foods and food simulants and the determination of substances in plastics and the selection of exposure to food simulants. Brussels:CEN.

Dagnon, KL, Ambadapadi, S, Shaito, A, Ogbomo, SM, DeLeon, V, Golden, TD, Rahimi, M, Nguyen, K, Braterman, PS, D'Souza, NA. 2009. Poly(L-lactic acid) nanocomposites with layered double hydroxides functionalized with ibuprofen. J Appl Polym Sci. 113:1905-1915. 
EFSA. 2008. Scientific opinion of the panel on food contact materials, enzymes, flavouring and processing aids (CEF) on 21st list of substances for food contact materials. EFSA J. 888890:1-14.

European Commission. 2004. Regulation no 1935/2004 of the European parliament and of the council of 27 October 2004 on materials and articles intended to come into contact with food. Off J Eur Comm. L. 338:4-17.

European Commission. 2007. Commission Directive 2007/19/EC of 30 March 2007 amending Directive 2002/72/EC relating to plastic materials and articles intended to come into contact with food and Council Directive 85/572/EEC laying down the list of simulants to be used for testing migration of constituents of plastic materials and articles intended to come into contact with foodstuffs. Off J Eur Comm. L. 91:1-11.

European Commission. 2002. Comission Directive of 6 August 2002 relating to plastic materials and articles intended to come into contact with foodstuffs. Off J Eur Comm. L. 220:18-58.

European Commission. 2009. Commission regulation (EC) No 450/2009 of 29 May 2009 on active and intelligent materials and articles intended to come into contact with food. Off J Eur Comm. L. 135:3-11.

Fomin, VA and Guzeev, VV. 2001. Biodegradable polymers, their present state and future prospects. Prog Rub Plast Technol. 17:186-204.

Garlotta, D. 2001. A literature review of poly(lactic acid). J Polym Environ. 9:63-84.

Katiyar, V, Gerds, N, Koch, CB, Risbo, J, Hansen, HCB, Plackett, D. 2010. Poly L-lactide nanocomposites via in situ polymerization of L-lactide. Polym Degr Stab. 95: 2563-2573. 
Katiyar, V, Gerds, N, Koch, CB, Risbo, J, Hansen, HCB, Plackett, D. 2011. Melt processing of poly (L-lactic acid) in the presence of organomodified anionic and cationic clays. J. Appl. Polym. Sci., accepted for publication. Lim, LT, Auras, R, Rubino, M. 2008. Processing technologies for poly(lactic acid). Prog Polym Sci. 33:820-852.

Lunt, J. 1998. Large-scale production, properties and commercial applications of polylactic acid polymers. Polym Degrad Stab. 59:145-152.

Mahboobeh, E, Yunus, WMZW, Hussein, Z, Ahmad, M, Ibrahim, NA. 2010. Flexibility improvement of poly(lactic acid) by stearate-modified layered double hydroxide. J Appl Polym Sci. 118:1077-1083.

Martin, O and Averous, L. 2001. Poly(lactic acid): plasticization and properties of biodegradable multiphase systems. Polym. 42:6209-6219.

Pan, PJ, Zhu, B, Dong, T, Inoue, Y. 2008. Poly(L-lactide)/layered double hydroxides nanocomposites: Preparation and crystallization behavior. J Polym Sci B Polym Phys. 46:2222-2233.

Pluta, M, Paul, MA, Alexandre, M, Dubois, P. 2006. Plasticized polylactide/clay nanocomposites. I. The role of filler content and its surface organo-modification on the physico-chemical properties. J Polym Sci B Polym Phys. 44:299-311.

Ray, SS and Bousmina, M. 2005. Biodegradable polymers and their layered silicate nano composites: In greening the 21st century materials world. Prog Mat Sci. 50:962-1079. 
Ray, SS, Maiti, P, Okamoto, M, Yamada, K, Ueda, K. 2002. New polylactide/layered silicate nanocomposites. 1. Preparation, characterization, and properties. Macromolecules. 35:31043110.

Schmidt, B, Petersen, JH, Bender Koch, C, Plackett, D, Johansen, NR, Katiyar, V, Larsen, EH. 2009. Combining asymmetrical flow field-flow fractionation with light-scattering and inductively coupled plasma mass spectrometric detection for characterization of nanoclay used in biopolymer nanocomposites. Food Addit Contam Part A Chem Anal Control Expo Risk Assess. 26:1619-1627.

Scientific Committee on Emerging and Newly Identified Health Risks (SCENIHR). Modified Opinion (after public consultation) on the appropriateness of existing methodologies to assess the potential risks associated with engineered and adventitious products of nanotechnologies [Internet]. 2006. Brussels: European Commission [cited 2010 Nov 17]. Available from: http://ec.europa.eu/health/ph_risk/documents/synth_report.pdf

Sharma, AK, Schmidt, B, Frandsen, H, Jacobsen, NR, Larsen, EH, Binderup, ML. 2010. Genotoxicity of unmodified and organo-modified montmorillonite. Mutat Res Genet Toxicol Environ Mutagen. 700:18-25.

Simon, P, Chaudhry, Q, Bakos, D. 2008. Migration of engineered nanoparticles from polymer packaging to food - a physicochemical view. J Food Nutrit Res. 47:105-113.

Sinclair, RG. 1996. The case for polylactic acid as a commodity packaging plastic. J Macromol SciPure Appl Chem. A33:585-597.

Sorrentino, A, Gorrasi, G, Vittoria, V. 2007. Potential perspectives of bio-nanocomposites for food packaging applications. Trends Food Sci Technol. 18:84-95. 
United States Environmental Protection Agency. 1996. Method 3052 - Microwave assisted acid digestion of siliceous and organically based matrices. Washington (MD): USA.

US Food and Drug Administration. Title 21: Food and Drugs [Internet]. 2010. Silver Spring, (MD):US Food and Drug Administration; [Cited 2010 Nov 16] Available from: http://www.accessdata.fda.gov/scripts/fcn/fcnDetailNavigation.cfm?rpt=iaListing\&id=2751

Zhang, Y, Zale, S, Sawyer, L, Bernstein, H. 1997. Effects of metal salts on poly(DL-lactide-coglycolide) polymer hydrolysis. J Biomed Mat Res. 34:531-538.

\section{List of Tables}

Table 1. Description of L-polylactide (PLA) and PLA/laurate-modified Mg-Al layered double hydroxide (PLA-LDH-C 12 ) based films.

Table 2. Molecular weights and polydispersity index (PDI) of L-polylactide (PLA) films and PLA/laurate-modified Mg-Al layered double hydroxide (PLA-LDH-C ${ }_{12}$ ) films before and after migration testing.

Table 3. Number-average molecular weight of each low molecular weight L-polylactide oligomer (OLLA) peak and relative concentration factor of the combined oligomers (Peak 1 to Peak 3 ) in the migrates as determined by gel permeation chromatography analysis. 
Table 4. Total migration and specific migration of components from PLA and PLA-LDH-C 12 nanocomposite materials

\section{List of figures:}

Figure 1. Gel permeation chromatograms of L-polylactide (PLA) and PLA/laurate-modified $\mathrm{Mg}-\mathrm{Al}$ layered double hydroxide (PLA-LDH-C 12 ) films before (BM) and after (AM) migration experiments: (a) PLA-PF, (b) PLA-PF1, (c) PLA-PF2, (d) PLA-PF3.

Figure 2. Gel permeation chromatography analyses of the raw migrates solutions. (a) Blank food simulant, (b) PLA-PF, (c) PLA-PF1, (d) PLA-PF2 and (e) PLA-PF3.

Figure 3: Electron photomicrographs of: (a) $\mathrm{LDH}-\mathrm{C}_{12}$ in SEM and TEM photomicrographs of migrates from (b) PLA-PF, (c) PLA-PF1, (d) PLA-PF2, (e) PLA-PF3 and (f) PLAPF3. 


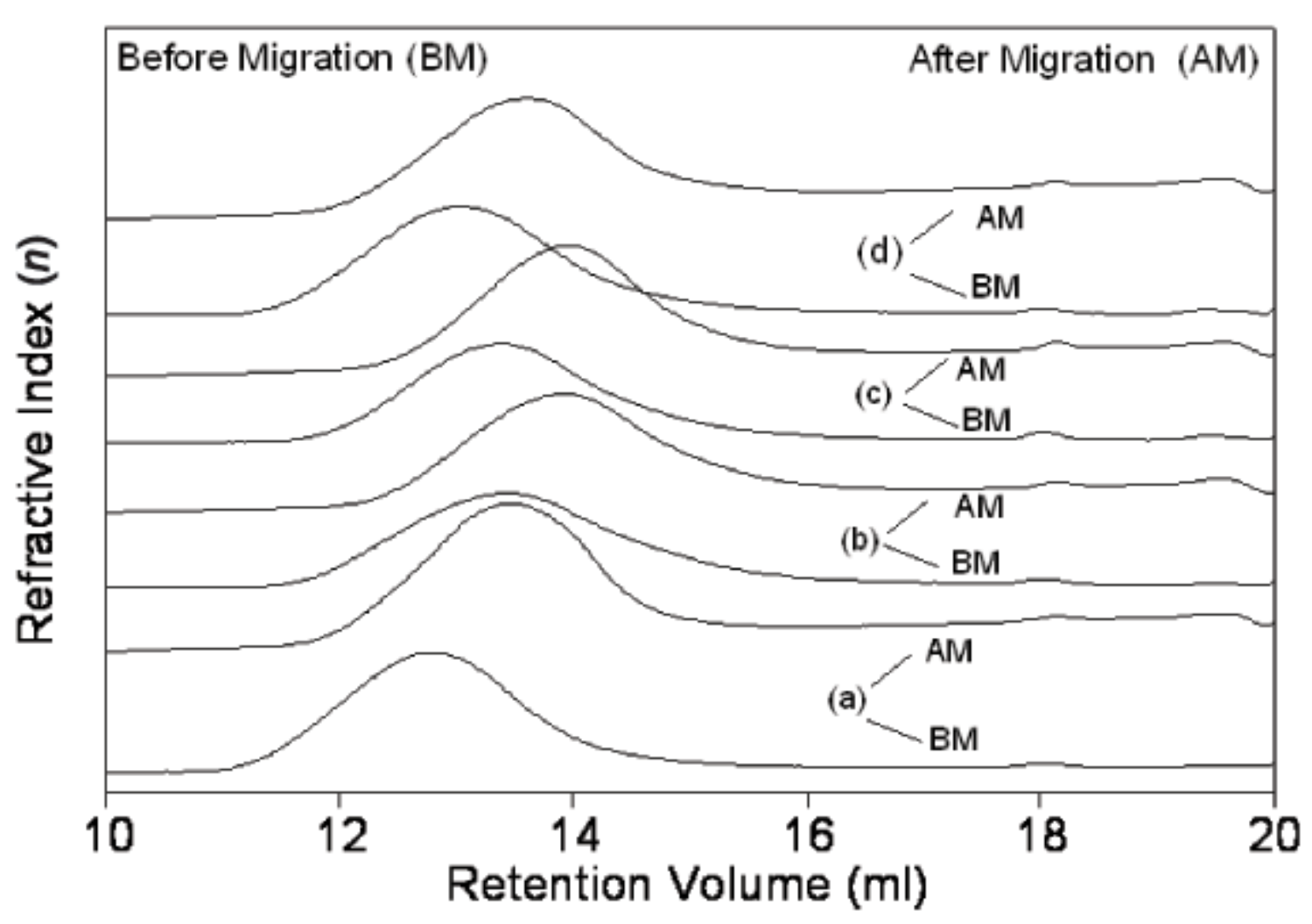

Figure 1. Gel permeation chromatograms of L-polylactide (PLA) and PLA/laurate-modified Mg-Al layered double hydroxide (PLA-LDH-C ${ }_{12}$ ) films before (BM) and after (AM) migration experiments: (a) PLA-PF, (b)PLA-PF1, (c) PLA-PF2, (d) PLA-PF3. 


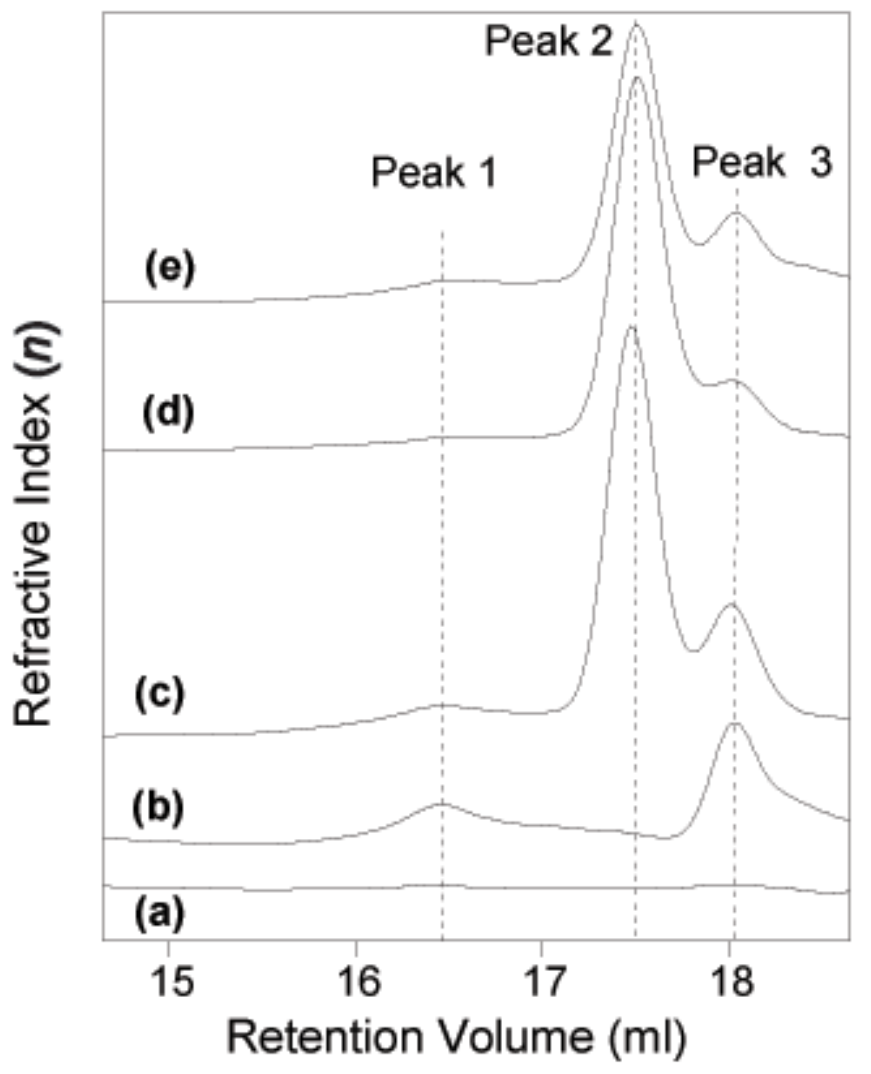

Figure 2. Gel permeation chromatography analyses of the raw migrates solutions. (a) Blank food simulant, (b) PLA-PF, (c) PLA-PF1, (d) PLA-PF2 and (e) PLA-PF3. 

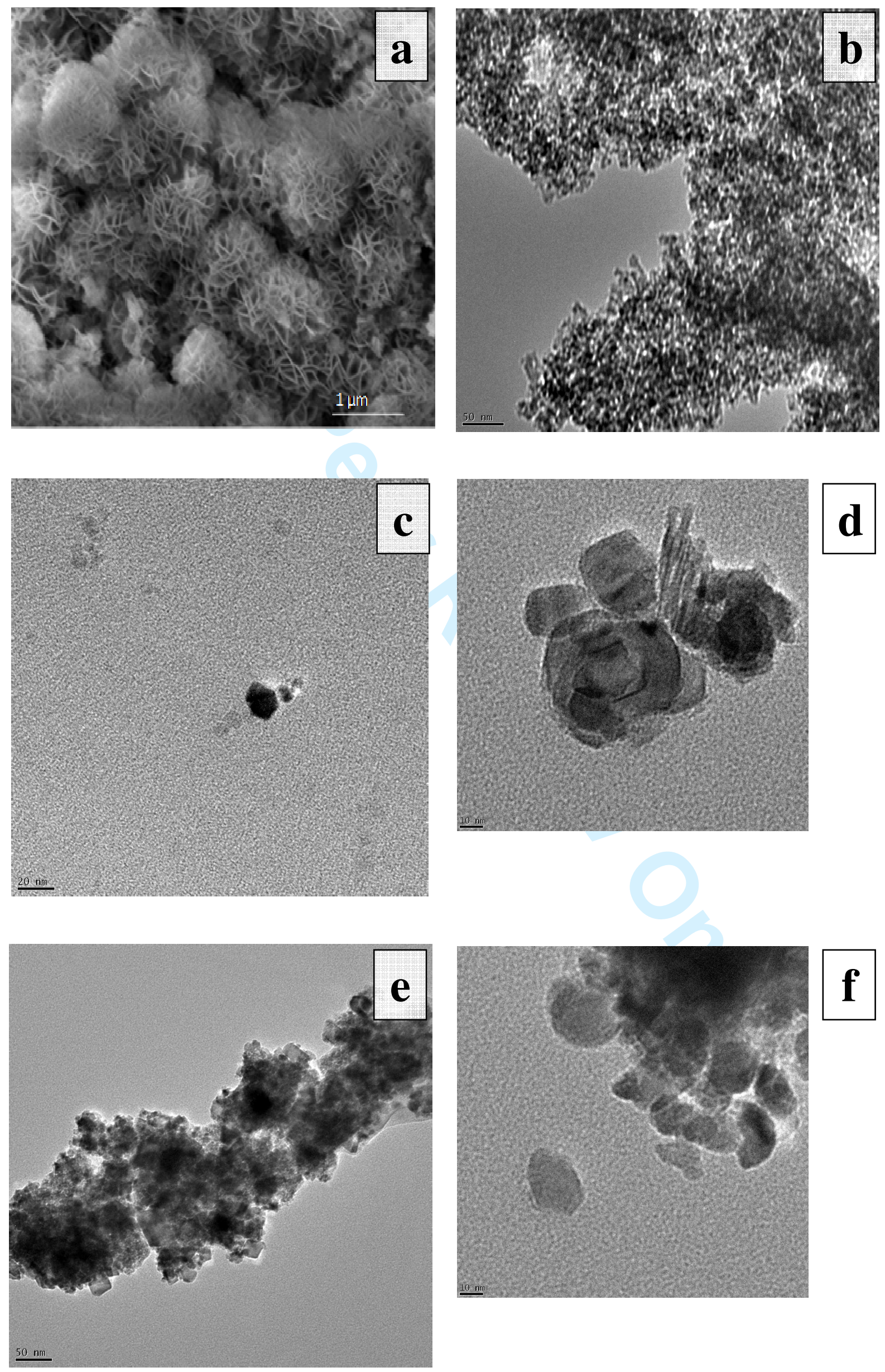

http://mc.manuscriptcentral.com/tfac Email: fac@tandf.co.uk 
Figure 3. Electron photomicrographs of: (a) LDH-C 12 in SEM and TEM photomicrographs of migrates from: (b) PLA-PF, (c) PLA-PF1, (d) PLA-PF2, (e) PLA-PF3 and (f) PLA-PF3. 
Table 1. Description of L-polylactide (PLA) and PLA/laurate-modified Mg-Al layered double hydroxide (PLA-LDH-C 12 ) based films.

\begin{tabular}{|c|c|c|}
\hline Film name & $\begin{array}{l}\text { LDH- } \mathrm{C}_{12} \text { loading } \\
\text { in film }\end{array}$ & Description \\
\hline PLA-PF & - & $\begin{array}{l}\text { Film from pellets produced by extrusion of NatureWorks }{ }^{\circledR} \\
\text { PLA granulates }\end{array}$ \\
\hline PLA-PF1 & $1.8 \%$ & $\begin{array}{l}\text { Film from extruded pellets, consisting of PLA granulates } \\
\text { and } 5.3 \% \mathrm{LDH}-\mathrm{C}_{12} \text {. Pellets were diluted } \mathrm{x} 3 \text { with PLA } \\
\text { granulates to prepare final LDH-C } \mathrm{C}_{12} 1.8 \% \text { loading. }\end{array}$ \\
\hline PLA-PF2 & $5.5 \%$ & $\begin{array}{l}\text { Film from extruded pellets, consisting of PLA granulates } \\
\text { and } 10 \% \text { of a } 50 \% \text { PLA } / 50 \% \mathrm{LDH}-\mathrm{C}_{12} \text { masterbatch }\end{array}$ \\
\hline PLA-PF3 & $1.8 \%$ & $\begin{array}{l}\text { Film from extruded pellets, consisting of PLA granulates } \\
\text { and } 10 \% \text { of a } 50 \% \text { PLA } / 50 \% \text { LDH-C }{ }_{12} \text { masterbatch which } \\
\text { was diluted } 3 \text { times with PLA granulates }\end{array}$ \\
\hline
\end{tabular}


Table 2. Molecular weights and polydispersity index (PDI) of L-polylactide (PLA) films and PLA/laurate-modified Mg-Al layered double hydroxide (PLA-LDH-C 12 ) films before and after migration testing.

\begin{tabular}{|c|c|c|c|c|c|c|c|}
\hline \multirow[t]{2}{*}{ Film } & $\mathrm{M}_{\mathrm{w}}(\mathrm{Da})$ & $\mathrm{M}_{\mathrm{n}}(\mathrm{Da})$ & PDI & $\mathrm{M}_{\mathrm{w}}(\mathrm{Da})$ & $\mathrm{M}_{\mathrm{n}}(\mathrm{Da})$ & $\overline{\mathrm{PDI}}$ & \multirow[t]{2}{*}{$\begin{array}{c}\% \text { Change in } \mathrm{M}_{\mathrm{n}} \\
\text { (during the test period) }\end{array}$} \\
\hline & \multicolumn{3}{|c|}{ Films before migration test } & \multicolumn{3}{|c|}{ Films after migration test } & \\
\hline PLA-PF & 182,800 & 107,100 & 1.7 & 160,700 & 81,500 & 2.0 & 24 \\
\hline PLA-PF1 & 116,800 & 55,400 & 2.1 & 118,900 & 34,100 & 2.5 & 38 \\
\hline PLA-PF2 & 108,400 & 61,900 & 1.8 & 83,300 & 38,100 & 2.0 & 38 \\
\hline PLA-PF3 & 151,600 & 90,100 & 1.7 & 125,700 & 57,800 & 2.2 & 36 \\
\hline
\end{tabular}


Table 3. Number-average molecular weight of each low molecular weight L-polylactide oligomer (OLLA) peak and relative concentration factor of the combined oligomers (Peak 1 to Peak 3 ) in the migrates as determined by gel permeation chromatography analysis.

\begin{tabular}{ccccc}
\hline Film & Peak 1 $\mathrm{M}_{\mathrm{n}}(\mathrm{Da})$ & Peak $2 \mathrm{M}_{\mathrm{n}}(\mathrm{Da})$ & Peak $3 \mathrm{M}_{\mathrm{n}}(\mathrm{Da})$ & $\begin{array}{c}\text { Relative concentration factor } \\
\text { of OLLA }\end{array}$ \\
\hline PLA-PF & 3,000 & Not Detected & 900 & 1 \\
PLA-PF1 & 3,600 & 1,400 & 1,100 & 2.0 \\
PLA-PF2 & Not Detected & 1,300 & 1,000 & 3.2 \\
PLA-PF3 & 3,600 & 1,600 & 1,000 & 1.4 \\
\hline
\end{tabular}


Table 4. Total migration and specific migration of components from PLA and PLA-LDH-C 12 nanocomposite materials

\begin{tabular}{ccccc}
\hline Sample & $\begin{array}{c}\text { Total Migration } \\
\left(\mathrm{mg} / \mathrm{dm}^{2}\right)\end{array}$ & $\begin{array}{c}\text { Laurate Migration } \\
\left(\mathrm{mg} / \mathrm{dm}^{2}\right)\end{array}$ & $\begin{array}{c}\text { LDH Migration }^{\text {a }} \\
\left(\mathrm{mg} / \mathrm{dm}^{2}\right)\end{array}$ & $\begin{array}{c}\text { Tin Migration } \\
\left(\mathrm{mg} / \mathrm{dm}^{2}\right)\end{array}$ \\
\hline PLA-PF & $2.5 \pm 0.6$ & $<0.2$ & $<0.1$ & $<0.0001$ \\
PLA-PF1 & $9.6 \pm 1.9$ & $3.4 \pm 0.3$ & $0.2 \pm 0.1$ & $<0.0001$ \\
PLA-PF2 & $31.9 \pm 7.4$ & $8.8 \pm 1.0$ & $2.2 \pm 0.1$ & $0.0025 \pm 0.0002$ \\
PLA-PF3 & $8.3 \pm 0.8$ & $2.6 \pm 0.2$ & $1.0 \pm 0.1$ & $0.0008 \pm 0.0001$ \\
Spike & $5.2 \pm 0.2$ & 0.2 & $4.0 \pm 0.4$ & $<0.0001$ \\
\hline
\end{tabular}

${ }^{a}$ Reported as $\mathrm{LDH}-\mathrm{C}_{12}$. 